Research Article

\title{
GA-Based Early Warning Method for Rock Burst with Microseismic and Acoustic Emission in Steeply Inclined Coal Seam
}

\author{
Yarong Xue $\mathbb{D}^{1},{ }^{1}$ Dazhao Song $\mathbb{D}^{1},{ }^{1}$ Zhenlei Li, $^{1}$ Jianqiang Chen, ${ }^{2}$ Xueqiu He, ${ }^{1,3}$ \\ Shengquan $\mathrm{He}^{1}$ and Donghui $\mathrm{Li}^{1}$ \\ ${ }^{1}$ School of Civil and Resources Engineering, University of Science \& Technology Beijing, Beijing 100083, China \\ ${ }^{2}$ Shenhua Xinjiang Energy Company Limited, Urumqi 830027, China \\ ${ }^{3}$ Zhong-an Academy of Safety Engineering, Beijing 100083, China
}

Correspondence should be addressed to Dazhao Song; song.dz@163.com

Received 10 July 2020; Revised 10 August 2020; Accepted 22 August 2020; Published 3 September 2020

Academic Editor: Xianjie Hao

Copyright (c) 2020 Yarong Xue et al. This is an open access article distributed under the Creative Commons Attribution License, which permits unrestricted use, distribution, and reproduction in any medium, provided the original work is properly cited.

Aiming at problem of low efficacy of early warning of rock burst in coal mine, a multisystem and multiparameter integrated early warning method based on genetic algorithm (GA) is proposed. In this method, firstly, the temporal-spatial-intensity information of energy incubation process of rock burst is deeply mined, and the multidimensional precursory characteristic parameter system of rock burst is constructed. Secondly, the genetic algorithm is used to train the historical monitoring data to obtain the optimal critical value and fitness value of each precursory characteristic parameter, and then the early warning index $W_{C}$ of each monitoring system is calculated. Finally, the integrated rock burst early warning index $I_{C}$ is obtained by synthesizing the early warning index $W_{C}$ of each system. The value of $I_{C}$ corresponds to the specific rock burst risk level of the mine. This method is applied to Wudong coal mine in Xinjiang, China. Based on the actual situation of the mine, a multidimensional precursory characteristic parameter system of rock burst is constructed, which includes energy deviation $\left(D_{E}\right)$, frequency ratio $\left(F_{r}\right)$, frequency deviation $\left(D_{F}\right)$, degree of dispersion $\left(D_{S}\right)$, and total high value of energy deviation $\left(D_{H}\right)$. After analyzing the rock burst danger status and risk level in the monitoring area, the early warning capability of this method is found to reach 0.896 . Combining with the specific prevention and control measures corresponding to different rock burst risk levels, it can provide effective guidance for the field work.

\section{Introduction}

Rock burst is one of the main dynamic disasters that affect the underground production of coal mine, which often causes serious consequences such as casualties and major property losses [1-4]. There are 139 mines threatened by rock burst in China, among which 26 are mines with a mining depth of more than one kilometer [5]. With the continuous extension of mining depth and intensity, rock burst disasters continue to escalate, and the number of mines threatened by rock burst is also increasing, which seriously affects the lives and property safety of coal miners.

In order to solve this problem, many scholars have made a lot of valuable research from the aspects of rock burst mechanism [6-9], monitoring method [10-12], disaster reduction measures [13, 14], protection means [15], and so on. Among them, the accurate monitoring and early warning method is the premise of the prevention and control of rock burst disaster.

At present, the monitoring and early warning methods for rock burst are mainly divided into two categories: traditional rock mechanics methods (e.g., drilling cutting method, coal and rock mass stress measurement, and core discing method) [16-21] and geophysical methods (e.g., electromagnetic radiation (EMR), microseismic (MS), and acoustic emissions (AE)) [11, 22-27]. In recent years, geophysics method has been widely used in underground because of its advantages of noncontact, data continuity, and automatic monitoring. At the same time, in order to reduce the risk of rock burst, coal production enterprises will 
generally choose the above-mentioned means to improve the accuracy of early warning. However, the monitoring principle and range of different monitoring technology and equipment are quite different, which may lead to the inconsistency of early warning results, thus affecting the judgment of relevant personnel on the actual dangerous situation and the measures taken and reducing the efficiency of the system.

Recognizing the problem of insufficient accuracy of single monitoring system, some excellent works have been carried out to establish multisystem monitoring methods to improve the early warning accuracy. He et al. [28] and $\mathrm{Li}$ et al. [29] combined MS and EMR and found that the energy and frequency of MS events had a "quiet period" within 1-3 days before the occurrence of rock burst, and the "quiet period" was corresponding to the peak intensity of EMR. Using this law, a coupling evaluation system was established to improve the prediction accuracy of rock burst. He et al. [30] studied the precursory information law of MS and AE monitoring system for rock burst events and proposed characteristic parameters. It found that it has obvious response law to the rock burst events of steeply inclined and extremely thick coal seam, which provided a solid foundation for the safe mining of such coal seam. Qin et al. [31] proposed an improved drill cutting method to make up for the defects of traditional drilling cutting method where the depth cannot reach the stress concentration area and cannot accurately reflect the internal stress variations of coal body. After the combination of improved drilling cutting method and the MS monitoring system, it overcomes the limitations of a single method and has achieved successful application in the underground. Lou et al. [32] carried out the uniaxial compression tests to the burst-prone coal and rock samples, and the results show that $\mathrm{AE}$ has a high correlation with the EME spectrum, and EME is usually accompanied by stress drop and high-intensity AE. This feature can be used to combine the two monitoring methods to improve the rock burst early warning accuracy of the working surface range. Tan et al. [33] used the energy release before the rock burst as a precursor to establish a multi-index risk warning system based on MS and EMR monitoring methods. Combined with the drilling bits method to determine the burst region, the targeted stress relief measures were taken to ensure the safe and efficient production of the mine. Xia et al. [34] extracted the energy deviation value and other parameters from the MS and AE monitoring data. After the capability test of each parameter with $R$-value scoring method, it is found that its early warning capability is good, and the prediction of rock burst can be more accurate after multisystem integration. Many applications of the multisystem monitoring methods [35-38] can also be found in various aspects of mining engineering.

All of the above researches have made beneficial exploration of the methods and indexes of monitoring and early warning of rock burst and achieved certain results in the field practice. However, in practice, it relies on artificially determining the influencing factors of coal rock stress and their weights, which has a certain degree of subjectivity. At the same time, the historical data of each monitoring system contains insufficient information mining and low data analysis efficiency, and the timeliness and accuracy of early warning have room to improve.

In recent years, the intelligent and precise mining of coal mine has become a hot issue. Using machine learning method to analyze and mine a large amount of historical data of various monitoring systems has become a new way to realize the underground intelligent monitoring and early warning. Faradonbeh et al. [39] used two robust clustering techniques of self-organizing map (SOM) and fuzzy c-mean (FCM) to find the latent relationship between the rock burstrelated parameters based on the compiled data samples from deep underground projects. And the result shows that the maximum tangential stress around the openings has a crucial role in rock burst clustering and has the most influence on the occurrence of strong and moderate rock burst types, which can be used as a method to predict the rock burst. Xue et al. [40] established a PSO-ELM rock burst prediction model using a database of 344 collected worldwide rock burst cases, which greatly increase the accuracy of rock burst prediction. Wu et al. [41] extracted six quantitatively characteristic parameters including the maximum tangential stress, the uniaxial compressive strength, and the uniaxial tensile strength from historical rock burst cases and established a rock burst prediction probability model based on the Least Squares Support Vector Machine (LSSVM) which was optimized by particle swarm optimization algorithm. Li et al. [42] established a rock burst risk evaluation model based on particle swarm optimization and BP neural network, which improved the accuracy of the standard BP model by $15 \%$ and has higher adaptability. Zhou et al. [43] applied the genetic algorithm and particle swarm optimization algorithm to the parameter optimization of support vector machine. The accuracy of the prediction results is higher than that of the measured samples, and it becomes an effective tool for monitoring and early warning of rock burst. Adoko et al. [44] used a large amount of on-site monitoring data to establish a rock burst prediction model based on fuzzy inference system (FIS) and adaptive neurofuzzy inference systems (ANFIS). The practical results show that the model has a high prediction accuracy for rock burst. Lin et al. [45] and Zhou et al. [46] used cloud model to classify and predict rock burst, using uniaxial compressive strength, tensile strength, tangential stress, rock brittleness coefficient, stress coefficient, and elastic energy index to establish the evaluation index system. The results show that the cloud model has higher discriminatory ability than Bayes, KNN, and RF methods, which can predict the rock burst event more accurately and reasonably. Li et al. [47] proposed a new Multiresolution Feature Fusion SVM (MRFF-SVM) recognition approach to compute a comprehensive feature vector for coal rock burst risk recognition and forecasting, and the risk of rock burst can be effectively monitored to reduce casualties and property losses. The above researches have made positive contribution to improving the early warning accuracy of rock burst and effectively improved the efficiency of data analysis.

Genetic algorithm is an adaptive global optimization probability search algorithm, which has strong robustness. 
Research shows that it has good application efficiency in dealing with multipeak problems, which means that it is suitable for solving complex mine monitoring data [48-51]. Therefore, we apply it to the optimization of rock burst danger critical value. Based on this, this paper puts forward a new multiparameter integrated early warning method for rock burst based on genetic algorithm and combines it with the measured data of No. B3+ 6 mining face of +450 mining level in Wudong coal mine (WCM), Xinjiang, China, carries out simulation research, and verifies its feasibility in MATLAB R2014a environment. The research results play an important role in the construction of continuous, real-time, and accurate monitoring and early warning system of rock burst and can effectively guide the on-site production and disaster relief work.

\section{Methods}

\subsection{Genetic Algorithm Optimization of Rock Burst Danger Critical Value}

2.1.1. Principle of Genetic Algorithm. Genetic algorithm (GA) is a kind of directed process search optimal solution algorithm that mimics the evolutionary mechanism of natural organisms in the target space. It can optimize the multiparameter or multicombination simultaneously. The essence is to use the mechanism of "survival of the fittest" in nature and finally select the samples with high environmental adaptability through iterative methods by genetic manipulation such as selection, crossover, and mutation $[52,53]$. The calculation process of GA is shown in Figure 1, and the main parameter values are shown in Table 1.

The indexes of the commonly used rock burst monitoring system, such as MS and AE, are discontinuous, multipeak, and noisy, which makes the critical value easy to fall into the local optimal solution in the process of optimization, and the search for the optimal critical value is closely related to the accurate early warning of rock burst. The GA naturally has excellent ability to find the global optimal solution, which makes it converge to the global optimal solution with a large probability in this complex environment, and the application performance is good. Specific steps are as follows:

(a) Combine the precursory characteristic parameters of each monitoring system into pairs and input them into the GA model as training samples.

(b) Automatically generate initial population at random.

(c) Calculate the fitness function of the initial population. The greater the fitness value is, the faster the fitness function converges.

(d) Determine whether the termination condition is satisfied, and if so, terminate the operation and output an optimal critical value of each characteristic parameter and a corresponding fitness value, and if not, perform step (e).

(e) Perform selection, crossover, and mutation operators, retain the individuals with high fitness value,

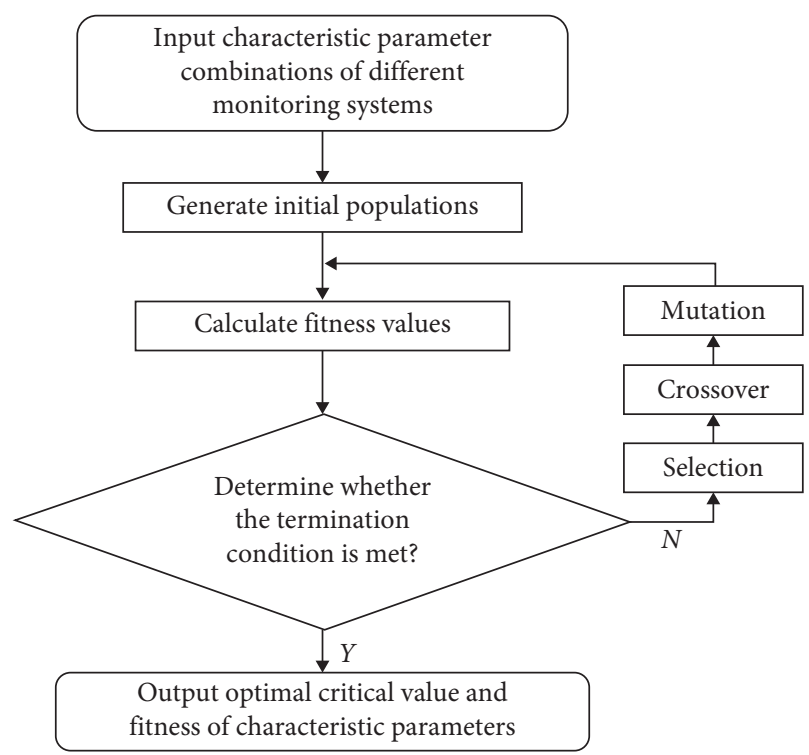

FIgURE 1: Genetic algorithm calculation process.

TABLE 1: Main parameter values of GA.

\begin{tabular}{|c|c|c|}
\hline Options & Descriptions & Values \\
\hline PopulationSize & Size of the population & 30 \\
\hline CrossoverFraction & $\begin{array}{l}\text { The fraction of the population at the } \\
\text { next generation, not including elite } \\
\text { children }\end{array}$ & 0.4 \\
\hline StallGenLimit & $\begin{array}{l}\text { Positive integer. The algorithm stops } \\
\text { if the average relative change in the } \\
\text { best fitness function value over } \\
\text { StallGenLimit generations is less } \\
\text { than or equal to TolFun (default } \\
\text { value is } 1 E-06 \text { ) }\end{array}$ & 20 \\
\hline MigrationFraction & $\begin{array}{l}\text { Scalar between } 0 \text { and } 1 \text { specifying the } \\
\text { fraction of individuals in each } \\
\text { subpopulation that migrates to a } \\
\text { different subpopulation }\end{array}$ & 0.2 \\
\hline EliteCount & $\begin{array}{l}\text { Positive integer specifying how many } \\
\text { individuals in the current generation } \\
\text { are guaranteed to survive to the next } \\
\text { generation }\end{array}$ & 6 \\
\hline
\end{tabular}

eliminate the individuals with low fitness, and generate new populations. Return to step (d) to continue the operation until the termination condition is met.

2.1.2. Fitness Function. The fitness function of genetic algorithm has no fixed requirement for form, so it has good adaptability and scalability. In this paper, the $R$-value scoring method of earthquake prediction capability is used as the fitness function of GA. The $R$-value scoring is a method proposed in the 1970s to evaluate the capability of earthquake prediction and has been widely used for decades with good application effect $[36,54,55]$. The idea is clear and easy to operate; neither false warnings nor missing warnings are encouraged. It can be calculated as follows: 


$$
R=a-d=\frac{n_{1}^{1}}{N_{1}}-\frac{n_{0}^{1}}{N_{0}},
$$

where $n_{1}^{1}$ represents the accurate prediction number of large energy tremors and rock bursts, $N_{1}$ represents the number of large energy tremors and rock bursts, $n_{0}^{1}$ represents the number of false warnings, $N_{0}$ represents the number of MS events that are neither rock burst nor large energy tremor, $a=n_{1}^{1} / N_{1}$ represents the early warning accuracy, and $d=$ $n_{0}^{1} / N_{0}$ represents the false warning rate. The closer the $R$ value is to 1 , the higher the accuracy of early warning is and the lower the rate of false or missing warning is.

\subsection{Extraction of Precursory Characteristic Parameters of Rock} Burst. Accurate and clear physical meaning of the precursory characteristic parameters of rock burst is the basis of the effective use of GA for early warning. At present, the monitoring information of each monitoring system is not fully utilized. Most of the mines still use a single critical value of energy or frequency to early warning rock burst [36], which does not consider the large amount of internal information such as amplitude and growth rate in the monitoring data, resulting in the low accuracy of early warning. Therefore, it is necessary to establish a precursory characteristic parameter system that can reflect the evolution features of underground tremor.

2.2.1. Temporal Characteristic Parameter. In general, the commonly used geophysical monitoring methods of rock burst include MS, AE, and EMR, which automatically record the variation of stress activities in coal and rock mass in time sequence. For example, the MS monitoring system will automatically collect and filter the tremor signal and calculate its occurrence time, three-dimensional coordinate position, energy, and so on. The greater the energy of the tremor occurred, the larger the fracture inside the coal rock mass is, which may induce a dynamic disaster, and the risk is evaluated accordingly.

However, the raw data of each monitoring system is mostly multipeak and noisy, and a single energy or frequency critical value is likely to cause false or missing warning. Therefore, based on the real-time data of monitoring system, the characteristic parameters including information such as growth rate and amplitude should be extracted to improve the efficiency of information use.

2.2.2. Spatial Characteristic Parameter. The tremor may occur in the far-field of rock stratum, near-field of surrounding rock, or local dangerous point of roadway, and it is in the dynamic change with the coal mining [56]. The smaller the positional dispersion of the tremor, the more concentrated the stress inside the rock mass. And the probability of dynamic disaster in the stress concentration area is significantly higher than that in other areas, so the description of the location information of tremors is also very important. For example, the MS monitoring system can be used to record the three-dimensional coordinates of the
MS events in order to establish spatial characteristic parameters.

2.2.3. Intensity Characteristic Parameter. There are two kinds of tremors caused by mining activities in underground mine: one is low-frequency, high-energy, which occurs in the high-level rock stratum and belongs to the category of MS; the other is high-frequency, low-energy, which occurs in the low-level surrounding rock and belongs to the category of AE. Studies have shown that the intensity of such tremors can reflect the change trend of the internal stress and rock burst risk of rock mass, and the commonly used early warning indicators include $b$ value, $A(b)$ value, and $P(b)$ value [57].

In summary, the multidimensional precursory characteristic parameters with clear physical significance and sensitivity extracted from a large amount of historical data of each monitoring system provide effective supports for the accurate early warning of rock burst danger.

\subsection{Early Warning Classification Criteria and Construction of Integrated Early Warning Index}

2.3.1. Early Warning Index of Single Monitoring System, $W_{C}$. While using GA to optimize the critical value of precursory characteristic parameter, firstly, combine the characteristic parameters from different dimensions of each system in pairs and then input different pairs of characteristic parameters into the GA to train the optimal critical value recorded as $V_{1}$ and $V_{2}$, and at the same time, the fitness value $R_{j}$ corresponding to $V_{1}$ and $V_{2}$ calculated by the fitness function is obtained, where $j$ represents the different characteristic parameter combination.

Compare the fitness values of different characteristic parameter combinations, take the largest one or two combinations as the characteristic parameters of the monitoring system, record the $i$-th of them as $a_{i}$ and $b_{i}$, and then compare them, respectively, with $V_{1}$ and $V_{2}$ to obtain the warning degree $W_{i}$. The calculation method is shown as follows:

$$
W_{i}= \begin{cases}0, & a_{i}<V_{1} \& b_{i}<V_{2}, \\ 1, & a_{i}<V_{1} \text { or } b_{i}<V_{2}, \\ 2, & a_{i}>V_{1} \& b_{i}>V_{2} .\end{cases}
$$

Then, the warning degree $W_{i}$ at the $i$-th moment and the fitness value $R_{j}$ are substituted into equation (3) to obtain the early warning index of single monitoring system $W_{C i}$ :

$$
W_{C i}=\sum\left(\frac{W_{i}}{\max \left(W_{i}\right)} \times \frac{R_{j}}{\sum R_{j}}\right),
$$

where $W_{i}$ represents the warning degree of different characteristic parameter combinations of a single system or different characteristic parameters of different sensors of a single system; $R_{j}$ represents the fitness value of different characteristic parameter combinations of a single system or different characteristic parameters of different sensors of a single system. 
2.3.2. Integrated Early Warning Index of the Multiple Monitoring System, $I_{C}$. In order to synthesize the early warning results of the precursory characteristic parameters of each system and form the real-time rock burst risk early warning index with unified early warning criteria and critical values, combined with the synthetical anomaly index method $[58,59]$, the integrated early warning index of rock burst risk is constructed and can be calculated as follows:

$$
I_{C i}=\sum\left(\frac{e-e^{1-W_{C i}}}{e-1} \times \frac{R_{C i}}{\sum R_{C i}}\right),
$$

where $W_{C i}$ represents the early warning index of a monitoring system and $R_{C i}$ represents the early warning capability of the corresponding monitoring system calculated with $R$ value scoring method.

The integrated early warning index $I_{C}$ can be obtained by the monitoring data of a certain period of time; in order to timely and clearly determine the current risk of rock burst, $I_{C}$ is divided into four levels, corresponding to no rock burst risk, weak rock burst risk, medium rock burst risk, and strong rock burst risk, respectively. As shown in Table 2, different prevention and control measures can be adopted for different risk levels.

A multisystem and multiparameter integrated early warning method for rock burst danger is established as above. This method can adjust the weight coefficient of each monitoring system in real time according to the calculation result. The higher the early warning capability, the greater the weight of the system, which can effectively improve the accuracy of early warning. The flowchart is shown in Figure 2.

\section{Case Study}

3.1. Basic Conditions of the No. B3+6 Working Face, WCM. WCM is located in Urumqi, Xinjiang, China. The overall geological section of the north and south mining area is shown in Figure 3, and up to now, the current mining situation of WCM is at No. $B 3+6+425 \mathrm{~m}$ working face. Both the No. $B 3+6$ and No. $B 1+2$ are classified as steeply inclined and extremely thick coal seam, and there is a rock pillar with 70-101 m thickness between them. The average inclination of the coal seam is $87^{\circ}$. The horizontal section full-mechanized top-coal caving mining technology is being adopted for mining, the ratio of mining to caving height is 1 : 7 , and the horizontal section height is $25 \mathrm{~m}$. Due to the special occurrence conditions of the coal seam, with the increase of the mining depth, a towering rock pillar is formed between the two coal seams. The rock pillar is affected by the horizontal tectonic stress and self-heavy stress, which causes the tilting effect of the intersection between the lower side of the rock column and the coal seam. Under the disturbance of mining, the elastic energy of rock mass accumulation is released through the coal body, which is easy to produce different degrees of dynamic disasters. There are six times of rock burst in the process of No. B3+6 coal seam mining.
At present, the mine has installed various monitoring systems such as ARAMIS M/E MS monitoring system and KJ623 AE monitoring system. The ARAMIS M/E is a particular MS monitoring system, which can automatically collect and filter seismic signals, and then calculates the occurrence time, released energy, and three-dimensional coordinates of both tremors and rock bursts. The south mining area of the WCM was surrounded by a total of 12 sensors, each sensor covered a range of $2 \mathrm{~km}$, and the layout of the sensors until 26 April 2017 when the last rock burst occurred is shown in Figure 4 (please refer to Li et al. 2014 for more details). The KJ623 AE monitoring system contains a total of 11 sensors that was installed on the coal and rock mass to collect $\mathrm{AE}$ events within a frequency range of $300-2000 \mathrm{~Hz}$. The sensitivity of the $\mathrm{AE}$ transducer was $65 \pm 3 \mathrm{~dB}(\mathrm{~V} / \mathrm{m} / \mathrm{s})$, the bolt was used as the AE conductor, and the sensor was installed on the bolt. The sensors are located at $30 \mathrm{~m}$ in front of the working face, and the spacing between each sensor is $30-40 \mathrm{~m}$. As the working face moves, the sensor layout moves accordingly.

According to the actual situation of WCM, the large energy mine tremors are defined as MS event with energy exceeding $1 \times 10^{5} \mathrm{~J}$. Taking the No. $B 3+6$ coal seam +450 horizontal working face of the coal mine as the research object, the MS and AE monitoring data of 2016/06/06-2017/ 12/28 time period are selected (see Tables S1-S2 in the Supplementary Material for complete field monitoring data of MS and AE). During this period, there are three rock burst events and ten large energy mine tremors in total, and the distribution of rock burst events is shown in Figure 5. Table 3 shows the specific manifestation records of these three rock burst events.

\subsection{Application of the Integrated Early Warning Method in WCM}

3.2.1. Construction of Precursory Characteristic Parameter System.

\section{(1) Temporal Characteristic Parameter}

(a) Frequency deviation $\left(D_{F}\right)$

The information of the mine tremor monitored by the MS system can reflect the internal stress of the rock mass. Prior to the occurrence of rock burst, the source of the MS increased and clustered anomaly compared to the previous normal mining period, which shows that the stress in the study area is close to the strength limit of coal and rock mass. Therefore, the frequency deviation value $\left(D_{F}\right)$ of a certain time window and sliding step length in the monitoring area is calculated. It can reflect the trend of the MS events over a period of time; the denser the MS tremor is in time sequence, the larger the value is. It can be calculated as follows:

$$
D_{F}=\frac{P_{F}-\overline{P_{F}}}{\overline{P_{F}}}
$$


TABLE 2: Rock burst hazard classification.

\begin{tabular}{lcc}
\hline Integrated early warning index of rock burst, $I_{C}$ & Levels of rock burst risk & State of rock burst risk \\
\hline $0 \leq I_{C}<0.25$ & I & No rock burst risk \\
$0.25 \leq I_{C}<0.5$ & II & Weak rock burst risk \\
$0.5 \leq I_{C}<0.75$ & III & Medium rock burst risk \\
$0.75 \leq I_{C} \leq 1$ & IV & Strong rock burst risk \\
\hline
\end{tabular}

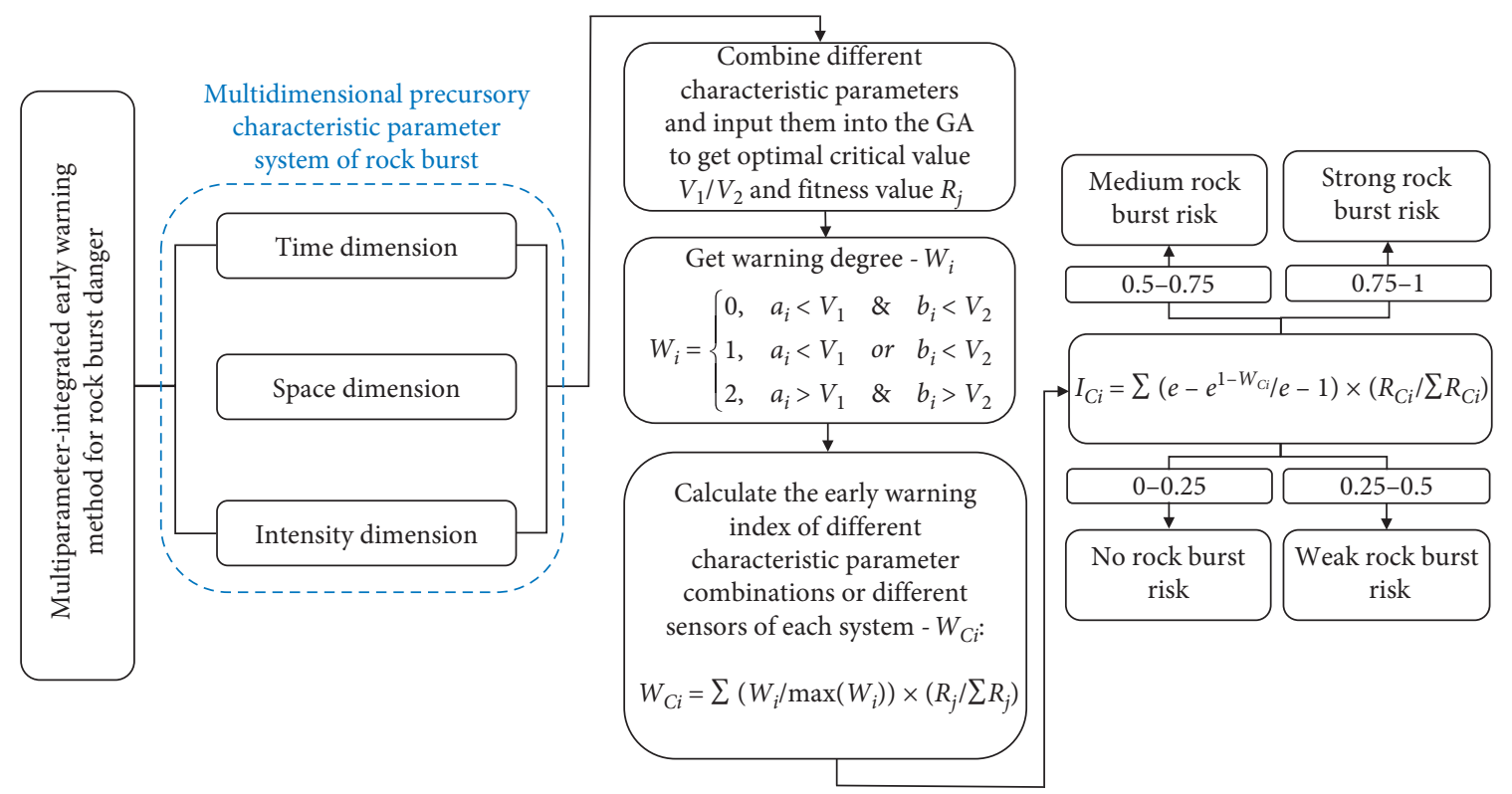

FIGURE 2: The flowchart of the multiparameter integrated early warning method for rock burst danger.

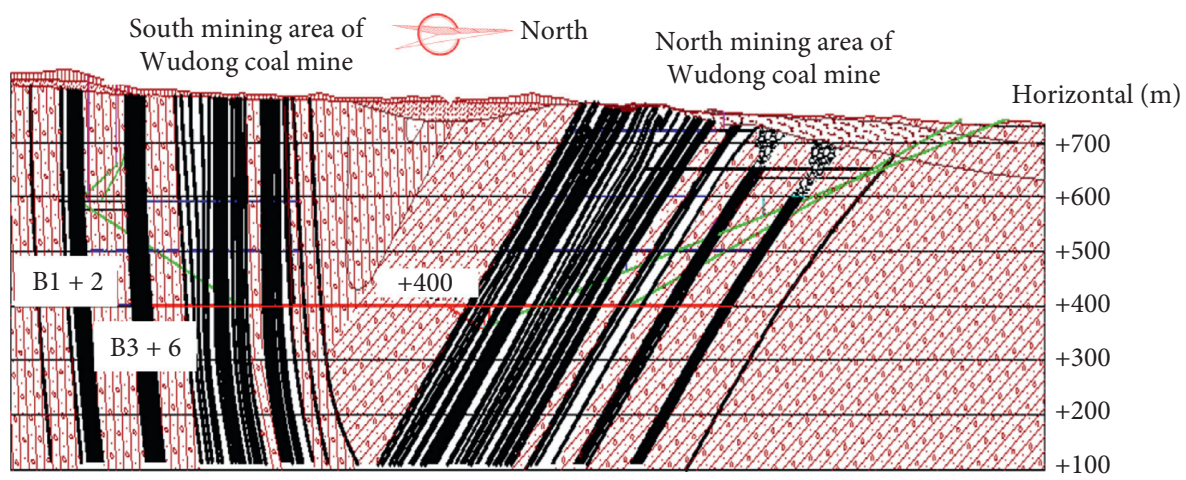

FIgURE 3: The overall geological section of WCM.

where $P_{F}$ represents the number of MS tremors within the first 24 hours and $\overline{P_{F}}$ represents the mean value of daily tremors during the period from the time of the last large energy mine tremor to the current time.

(b) Frequency ratio $\left(F_{r}\right)$

The higher the frequency of MS tremor is, the more frequent the stress activities in the rock mass are and the more likely the rock burst is to be induced; otherwise, the less likely it is. Therefore, the frequency ratio $\left(F_{r}\right)$ of the characteristic parameter is defined, and the calculation method is as follows:

$$
F_{r}=\frac{\overline{F_{t_{1}}}}{\overline{F_{t_{2}}}}
$$

where $\overline{F_{t_{1}}}$ represents the average number of the MS tremors in the previous $t_{1}$ time period and $\overline{F_{t_{2}}}$ represents the average number of the MS tremors in the previous $t_{2}$ time period, in which $t_{1}<t_{2}$. According to the actual situation of WCM, let $t_{1}=8 \mathrm{~h}$ and $t_{2}=48 \mathrm{~h}$.

(2) Spatial Characteristic Parameter. The studies show that the smaller the dispersion of the source position of the MS 


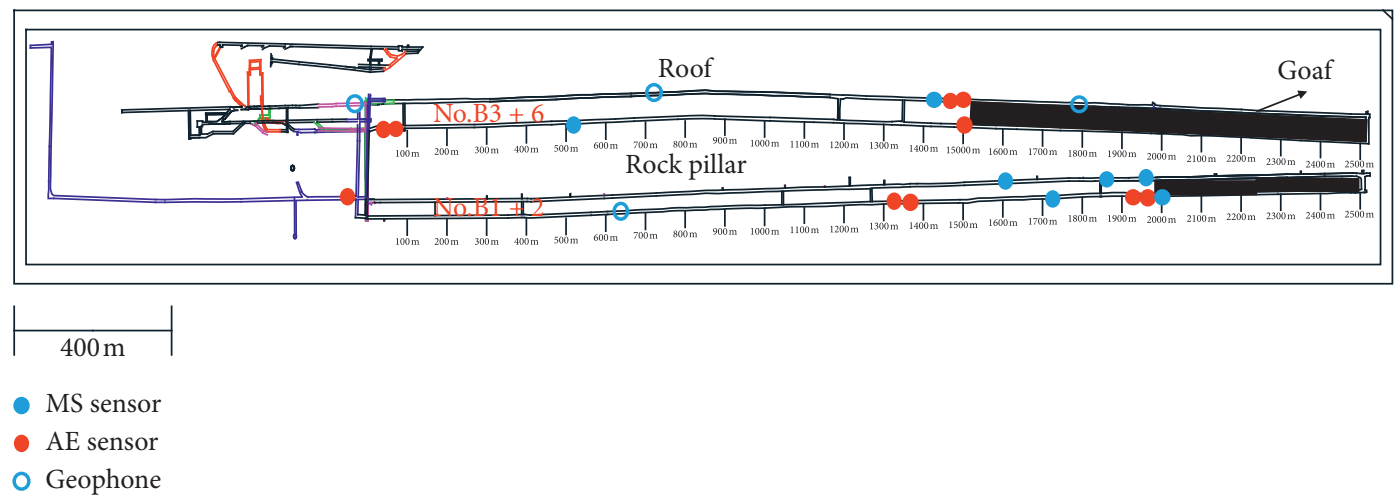

FIgURE 4: Network layout of MS and AE monitoring system in No. $B 3+6$ coal seam +450 horizontal working face of WCM during the research period.



FIGURE 5: The distribution map of MS events with energy exceeding $1 \times 10^{3} \mathrm{~J}$ in No. $B 3+6$ coal seam +450 horizontal working face WCM during 2016/06/06-2017/12/28.

tremor in a period of time, the greater the possibility of a large energy tremor after that; the greater the energy of the MS tremor, the greater the possibility of a large energy tremor occurring after the same degree of dispersion. Therefore, degree of dispersion $\left(D_{S}\right)$ is defined by combining the two dimensions of the dispersion and energy, which is a quantitative description of the risk of rock burst. The calculation method is as follows.

First, calculate the weighted average distance $\left(d_{s}\right)$ of all MS tremors in the time window by

$$
d_{s}=\frac{\sqrt{\sum_{i=1}^{n} w_{i}\left[\left(x_{i}-\bar{x}\right)^{2}+\left(y_{i}-\bar{y}\right)^{2}+\left(z_{i}-\bar{z}\right)^{2}\right]}}{n},
$$

where $w_{i}$ represents the energy of the $i$-th MS tremor, $x_{i} / y_{i} / z_{i}$ represent the coordinates of the $i$-th MS tremor, $\bar{x} / \bar{y} / \bar{z}$ represent the average coordinates of the MS tremors within the time window, and $n$ represents the number of MS tremors within the time window.
Second, calculate the characteristic energy $\left(E_{r}\right)$ by

$$
E_{r}=E_{\text {max }}+E_{\text {median }},
$$

where $E_{\text {max }} / E_{\text {median }}$ represents the maximum/median energy of MS tremors within the time window.

Third, sort $d_{s}$ of all MS tremors in the time window from small to large, and find the MS tremors which located in 1.2, 7.0, 27.5, 80.8, 88.5, 95.0, and 98.0 quantiles. Average the energy of the MS tremors within $1 \mathrm{~m}$ around the above seven MS tremors to get the critical characteristic energy $\left(E_{c}\right)$, and then use interpolation to connect the above seven points to obtain the curve of $E_{c}$ which can be seen in Figure 6. Each $E_{r}$ point can find its corresponding $E_{c}$ on the curve, and then $D_{S}$ can be calculated as follows:

$$
D_{s}=\lg \left(\frac{E_{r}}{E_{c}}+1\right) \text {. }
$$

\section{(3) Intensity Characteristic Parameter}

(a) Energy deviation $\left(D_{E}\right)$

The research shows that the intensity of mine tremors' energy caused by mining activities can reflect the variation trend of rock stress and rock burst risk. Prior to the occurrence of rock burst, microcracks propagated and connected, eventually forming macrofractures, leading to an abnormal increase in MS/AE energy, and $D_{E}$ was higher than before. Therefore, the energy deviation $\left(D_{E}\right)$ of the MS and AE monitoring systems is defined as precursor to warn rock burst hazard. It can be calculated as follows:

$$
D_{E}=\frac{P_{E}-\overline{P_{E}}}{\overline{P_{E}}}
$$

where $P_{E}$ represents the total energy of MS/AE monitoring system within the first 24 hours and $\overline{P_{E}}$ represents the mean value of daily MS/AE monitoring system's energy during the period from the time of the last large energy mine tremor to the current time.

(b) Total high value of energy deviation $\left(D_{H}\right)$ 
TABLE 3: On-site rock burst manifestation records.

\begin{tabular}{|c|c|c|c|c|}
\hline Date & $\begin{array}{c}\text { Location of } \\
\text { working face }(\mathrm{m})\end{array}$ & Location of MS source & $\begin{array}{l}\text { MS energy } \\
(\mathrm{J})\end{array}$ & Damage form and degree \\
\hline $\begin{array}{l}2016 / \\
11 / 24\end{array}$ & 2026 & $\begin{array}{l}\text { Located in the } B 2-B 3 \text { rock wall, } \\
12 \mathrm{~m} \text { away from the } B 3 \text { bottom } \\
\text { plate }\end{array}$ & $9.5 \times 10^{6}$ & $\begin{array}{l}\text { Upper wall moved } 0.3 \mathrm{~m} \text {, lower wall moved } 0.5 \mathrm{~m} \text {, floor } \\
\text { heaved by } 0.4 \mathrm{~m} \text {, damage to hydraulic props }\end{array}$ \\
\hline $\begin{array}{l}2017 / \\
02 / 01\end{array}$ & 1824 & $\begin{array}{c}\text { Located at } 9 \mathrm{~m} \text { from the } B 6 \text { roof } \\
\text { slate }\end{array}$ & $2.1 \times 10^{8}$ & $\begin{array}{c}\text { Upper wall moved } 0.3-0.7 \mathrm{~m} \text {, lower wall moved } 0.5-1.3 \mathrm{~m} \text {, } \\
\text { damage to belt conveyor }\end{array}$ \\
\hline $\begin{array}{l}2017 / \\
04 / 26\end{array}$ & 1568 & $\begin{array}{c}\text { Located in the } B 2-B 3 \text { rock pillar, } \\
35 \mathrm{~m} \text { away from the } B 3 \text { bottom } \\
\text { plate }\end{array}$ & $2.2 \times 10^{6}$ & $\begin{array}{c}\text { Lower wall moved } 0.3-0.5 \mathrm{~m} \text {, floor heaved by } 0.2-0.3 \mathrm{~m} \text {, } \\
\text { damage to hydraulic props and belt conveyor, reversed } \\
\text { loader change direction }\end{array}$ \\
\hline
\end{tabular}

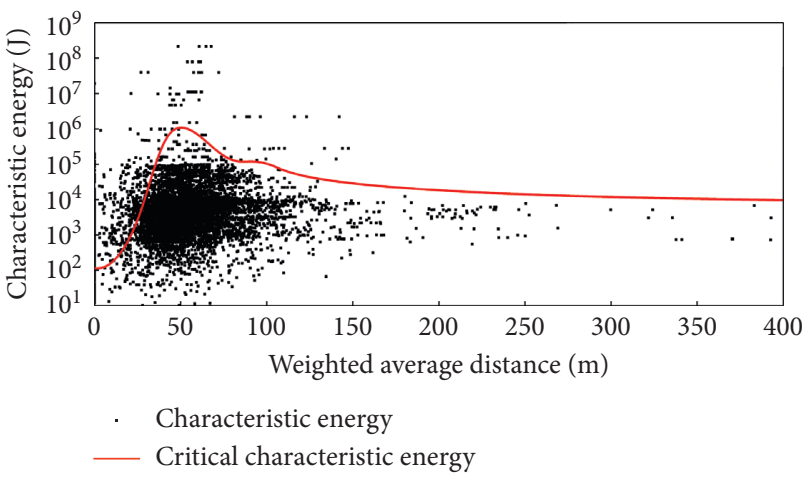

FIgURE 6: The critical characteristic energy curve.

The higher $D_{E}$ indicates that the stress variation in the rock and the risk of rock burst are more severe than in the past. The total high value of energy deviation $\left(D_{H}\right)$ is extracted as the precursory characteristic parameter to improve the accuracy of rock burst risk early warning. The calculation method is shown as follows:

$$
N_{i}= \begin{cases}1, & \left|D_{E i}\right| \geq C, \\ 0, & \left|D_{E i}\right|<C,\end{cases}
$$

where $D_{E i}$ represents the $i$-th $D_{E}$ and $N_{i}$ represents the judgment result corresponding to the $i$-th $D_{E}$ with the critical value $C$. One has

$$
D_{H i}=\sum_{i=1}^{n} N_{i},
$$

where $n$ represents the length of time window and $D_{H i}$ represents the total number of high values exceeding the critical value $C$ corresponding to the $i$-th $D_{E}$. According to the actual situation of WCM, let $C=20$.

In summary, the multidimensional precursory characteristic parameter system of rock burst in WCM shown in Figure 7 can be obtained.

The time window and sliding step length of the precursory characteristic parameters should be set according to the actual situation of WCM. If they are too long, the detailed characteristics of the data will be lost; if they are too short, the credibility of the data will be reduced (a large number of invalid data will be produced). Therefore, using the 24-hour time window and 1-hour sliding step length and taking the monitoring data within 1.5 months before and after the "02.01" rock burst as an example, plot the time series curve of precursory characteristic parameters as shown in Figure 8. For convenience of explanation, the MS tremors with energy larger than $1 \times 10^{5} \mathrm{~J}$ are numbered according to the sequence of (1)-(5).

In the case of a single precursory characteristic parameter, it is considered as accurate warning that there are significant fluctuations within two days before the occurrence of a rock burst or large energy mine tremor (hereinafter referred to as "event") and exceeds the corresponding critical value; otherwise, it is false or missing warning. It can be seen from Figure 8 that the time series variations of these six characteristic parameters have a good correlation with events and can reflect the precursory early warning information of events from different dimensions of time, space, and intensity.

At the same time, it is found that the warning results of the events between different characteristic parameters are not the same; Figures $8(\mathrm{c})-8(\mathrm{e})$ are accurate for the (4) event and Figures $8(\mathrm{f})$ and $8(\mathrm{~g})$ are not. After analyzing the reasons, Figures $8(\mathrm{c})-8(\mathrm{e})$ are characteristic parameters of the MS monitoring system, and Figures 8(f) and $8(\mathrm{~g})$ are characteristic parameters of the AE monitoring system. Because different monitoring systems have different principles and ranges, that is, the MS system monitors the fracture of high-field coal and rock mass, its vibration frequency is less than $150 \mathrm{~Hz}$, the monitoring range is $10 \mathrm{~km}$, the $\mathrm{AE}$ system monitors the crack propagation of low-field coal and rock mass, its vibration frequency is between 150 and $3000 \mathrm{~Hz}$, and the monitoring range is $200 \mathrm{~m}$. The two systems can separately monitor the whole process of rock burst incubation and development, and the monitoring results complement each other, so there are certain differences. Apart from this, due to the different network layout of each monitoring system, most of the AE sensors are arranged not far from the front of the working face, while the MS sensors are arranged in a wide range, which can reach the whole mining area. Because of the complex underground 


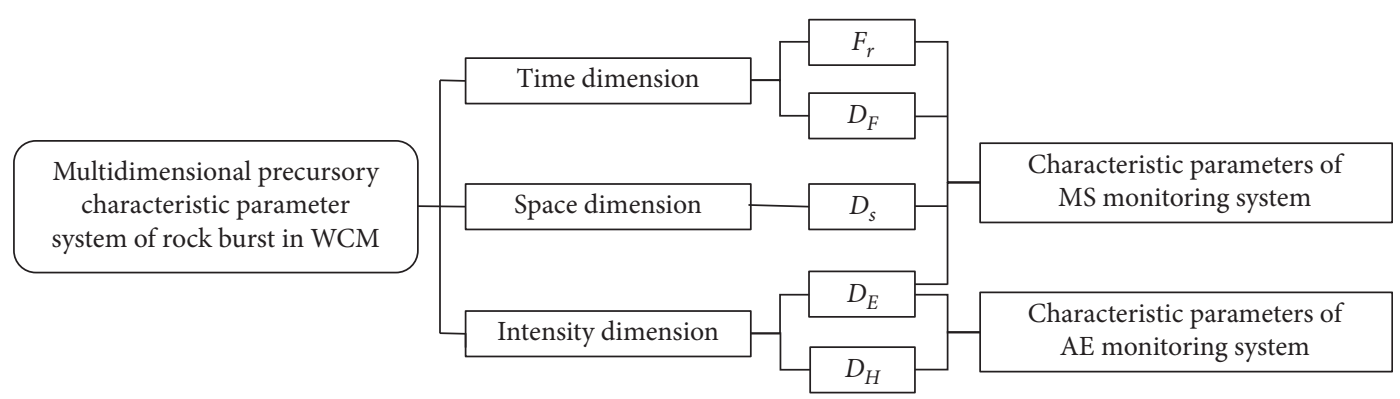

FIgURE 7: The multidimensional precursory characteristic parameter system of rock burst in WCM.

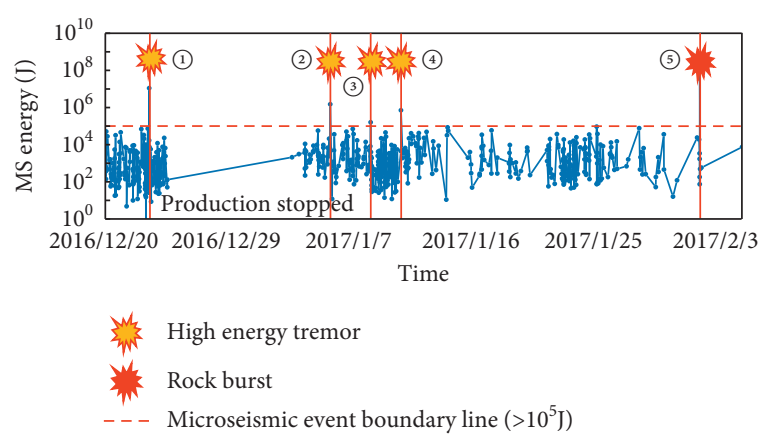

(a)

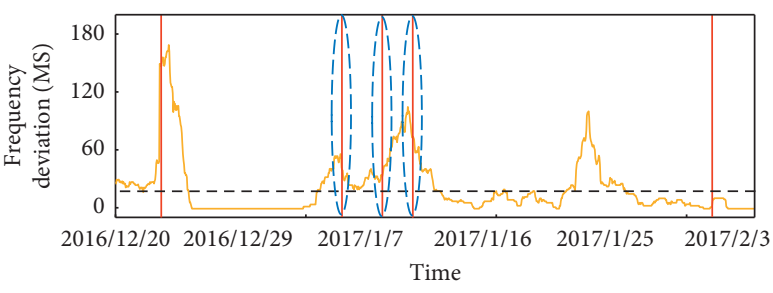

- - - Optimal threshold of characteristic parameters

$\therefore$ Correct warning

(c)

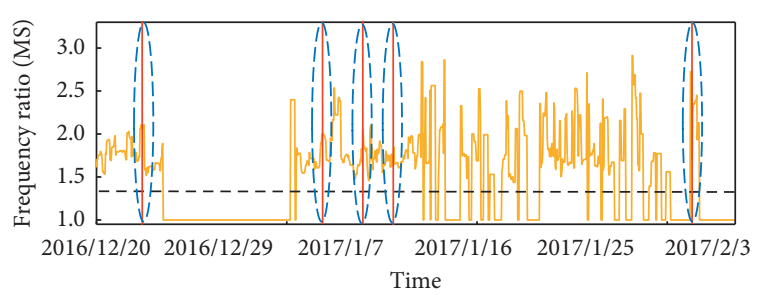

- - - Optimal threshold of characteristic parameters $\therefore$ Correct warning

(e)

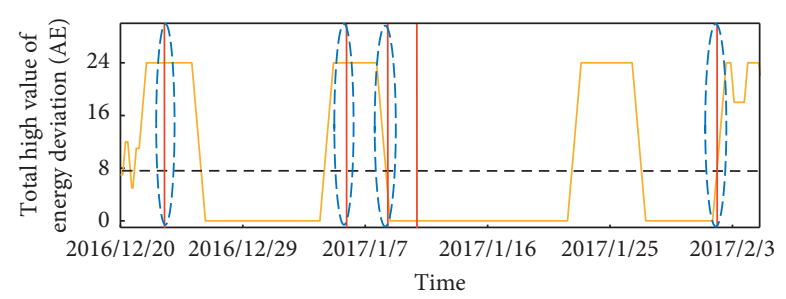

- - - Optimal threshold of characteristic parameters

$\therefore$ Correct warning

(g)

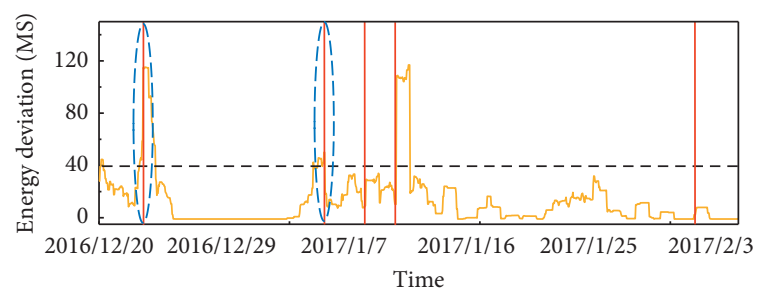

- - - Optimal threshold of characteristic parameters

..) Correct warning

(b)

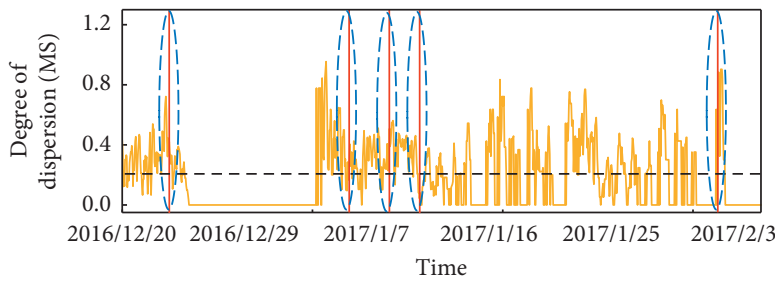

- - - Optimal threshold of characteristic parameters

- Correct warning

(d)

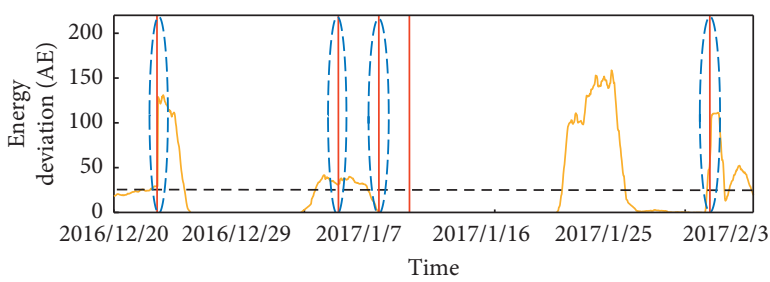

- - - Optimal threshold of characteristic parameters

$\therefore$ Correct warning

Figure 8: The time series curve of each precursory characteristic parameters, (a) energy of MS event; (b) time series curve of $D_{E}$ of MS system; (c) time series curve of $D_{F}$ of MS system; (d) time series curve of $D_{S}$ of MS system; (e) time series curve of $F_{r}$ of MS system; (f) time series curve of $D_{E}$ of AE system; (g) time series curve of $D_{H}$ of AE system (1) 2016/12/23 5:50:37, $1.10 E+07 \mathrm{~J}$; (2) 2017/1/5 14:45:25, $1.50 E+06$ J; (3) $2017 / 1 / 814: 23: 01,1.60 E+05$ J; (4) 2017/1/10 20:07:07, $7.10 E+05$ J; (5) 2017/2/1 21:51:21, $2.10 E+08$ J. 
environment, the signals collected by different sensors may be interfered, so the results may vary from system to system. By using this feature, the characteristic parameters extracted from different monitoring systems can be integrated synthetically, which can make them complement each other's advantages and more efficiently and accurately early warning the risk of rock burst.

\subsubsection{Critical Value Optimization and Early Warning Index} Classification. The characteristic parameters of different monitoring systems are combined into pairs and input into the GA model, and the training is carried out in the computer simulation environment. The paper uses MATLAB R2014a to compile the code and the operation process is shown in Figure 9. The code is run under the following environment: processor: AMD Ryzen 5 4600U with Radeon Graphics $2.10 \mathrm{GHz}$, RAM: $16 \mathrm{~GB}, 64$ bits, and Windows 10 .

According to the calculation results shown in Table 4, one or two pairs of characteristic parameters with the highest fitness value are selected as the precursory characteristic parameters of each monitoring system, and $W_{i}$ of different monitoring systems can be obtained by substituting into equation (2), and then use equation (3) to get $W_{C i}$ of each monitoring system. Finally, according to the above results, $I_{C}$ can be obtained, and the different values correspond to four levels of no, weak, medium, and strong rock burst risk. The flowchart of multisystem and multiparameter integrated early warning method of rock burst risk in WCM is shown in Figure 10.

3.3. Early Warning Results and Analysis. Due to the complex and changeable underground mine conditions, the sensors of each monitoring system are interfered by multiple factors, which may lead to problems such as the discontinuity of the monitoring data or the instability of the monitoring time. When integrating multisystem monitoring data, it is necessary to ensure that the monitoring data of each sensor is in the same time period. Therefore, in order to use as many sensors as possible to provide sufficient precursory information of rock burst risk, the monitoring data from 2017/03/ 07 to $2017 / 12 / 28$ is selected for integration.

There are ten events from $2017 / 03 / 07$ to $2017 / 12 / 28$, including "04.26" rock burst event. In order to avoid systematic errors, it is considered that the MS events with energy larger than $1 \times 10^{5} \mathrm{~J}$, which occurred at a very close time and geographical coordinate, belong to the same large energy event. For example, the four consecutive MS events which occurred on September 21 are the same event; therefore, it is finally considered that six events have occurred in this time period, numbered according to the sequence of (1)-(6). The $R$-value scoring method (equation (1)) is used to calculate the early warning capability of each monitoring system in this time period. The basis for judging the success or failure of early warning is as follows: if $I_{C}$ exceeds 0.5 within three days before the event, the early warning is successful; otherwise, it has failed. The results are shown in Table 5.

Using equation (4) to calculate the integrated early warning index of rock burst risk $I_{C}$, the result is shown in Figure 11.

As shown in the red boxes in Figure 11, $I_{C}$ has exceeded 0.5 within three days of the events. According to Table 2, it is judged as level III or IV rock burst risk, indicating that the variation of the index has an obvious correlation with the occurrence of the event, which can provide effective early warning for the event. The index synthesizes the multidimensional characteristic parameters of multisystem and provides precursory information for rock burst danger. According to the $R$-value scoring method, the early warning capability is $R=6$ / $6-735 / 7119=0.896$, which is significantly higher than the early warning capability of MS single system of 0.763 and the early warning capability of AE single system of 0.621 . This is because when the multisystem early warning results are integrated, different monitoring systems provide each other with early warning criterion and multidimensional characteristic parameters' early warning results verify each other, eliminating the influence of single system accidental factors, thus improving the early warning accuracy and finally making its early warning capability higher than that of a single monitoring system.

The integrated early warning index $I_{C}$ can effectively evaluate the risk degree of internal dynamic disaster of coal and rock mass, and it is a single index integrating multiple systems and parameters, which is easy to read and can provide early warning information for mines in real time and quantitatively. More efficient and accurate prevention and control of underground dynamic disasters, thus avoiding major casualties and property losses, are of great significance to the production field.

\section{Early Warning Verification}

In practical applications, for newly installed monitoring systems or mines, mining new coal seams, the data to be monitored shall be at least two months, so as to ensure that there is sufficient data for training to avoid overfitting; if different monitoring systems have been installed and the mining coal seams have not been replaced in a certain period of time, the method described in Section 2 can be directly applied to calculate the integrated early warning index $I_{C}$.

The specific calculation method is as follows: take 24 hours as the time window, 1 hour as the sliding step to calculate the characteristic parameters, and one month as the drawing time window. Taking the monitoring data of the No. B3+6 coal seam +450 horizontal working face in January 2018 as an example, there were four MS tremors with energy over $1 \times 10^{5} \mathrm{~J}$. Similarly, the two MS tremors that occurred on $01 / 06$ belong to the same event. For the convenience of explanation, 


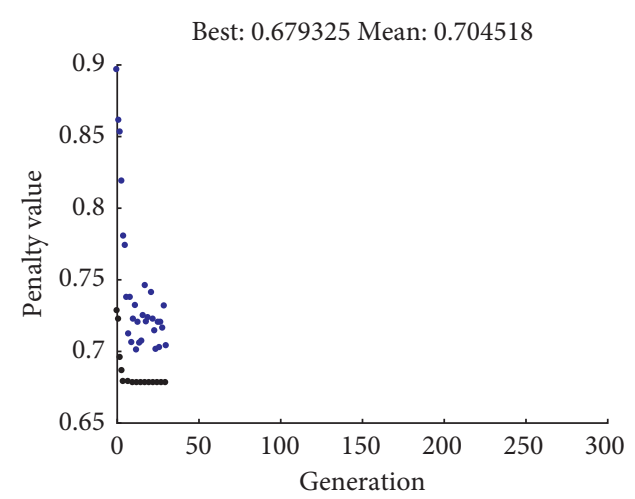

- Best penalty value

- Mean penalty value

(a)

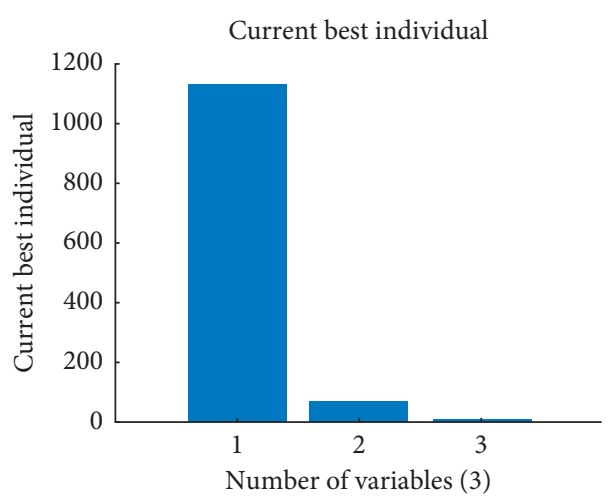

(b)

Figure 9: The operation process of GA in MATLAB R2014a. (a) The change of the best fitness value and the mean penalty value during the operation. (b) The vector value of the best fitness individual in each generation.

TABle 4: Optimal critical value and fitness of precursory characteristic parameters.

\begin{tabular}{|c|c|c|c|c|}
\hline Name of the monitori & gg system & Optimal critical value $V_{1}$ & Optimal critical value $V_{2}$ & Fitness value $R$ \\
\hline \multirow{3}{*}{ ARAMIS M/E MS monitoring system } & & $D_{s}$ & $F_{r}$ & 0.609 \\
\hline & Optimal combination & 0.364 & 1.594 & \\
\hline & Suboptimal combination & $\begin{array}{c}D_{E} \\
39.087\end{array}$ & $\begin{array}{c}D_{F} \\
40.815\end{array}$ & 0.406 \\
\hline \multirow{5}{*}{ KJ623 AE monitoring system } & & $D_{E}$ & $D_{H}$ & \\
\hline & $1 \#$ sensor & 107.061 & 12.639 & 0.671 \\
\hline & 2\# sensor & 26.585 & 7.644 & 0.423 \\
\hline & 3\# sensor & 115.997 & 14.848 & 0.715 \\
\hline & 4\# sensor & 105.237 & 12.367 & 0.515 \\
\hline
\end{tabular}

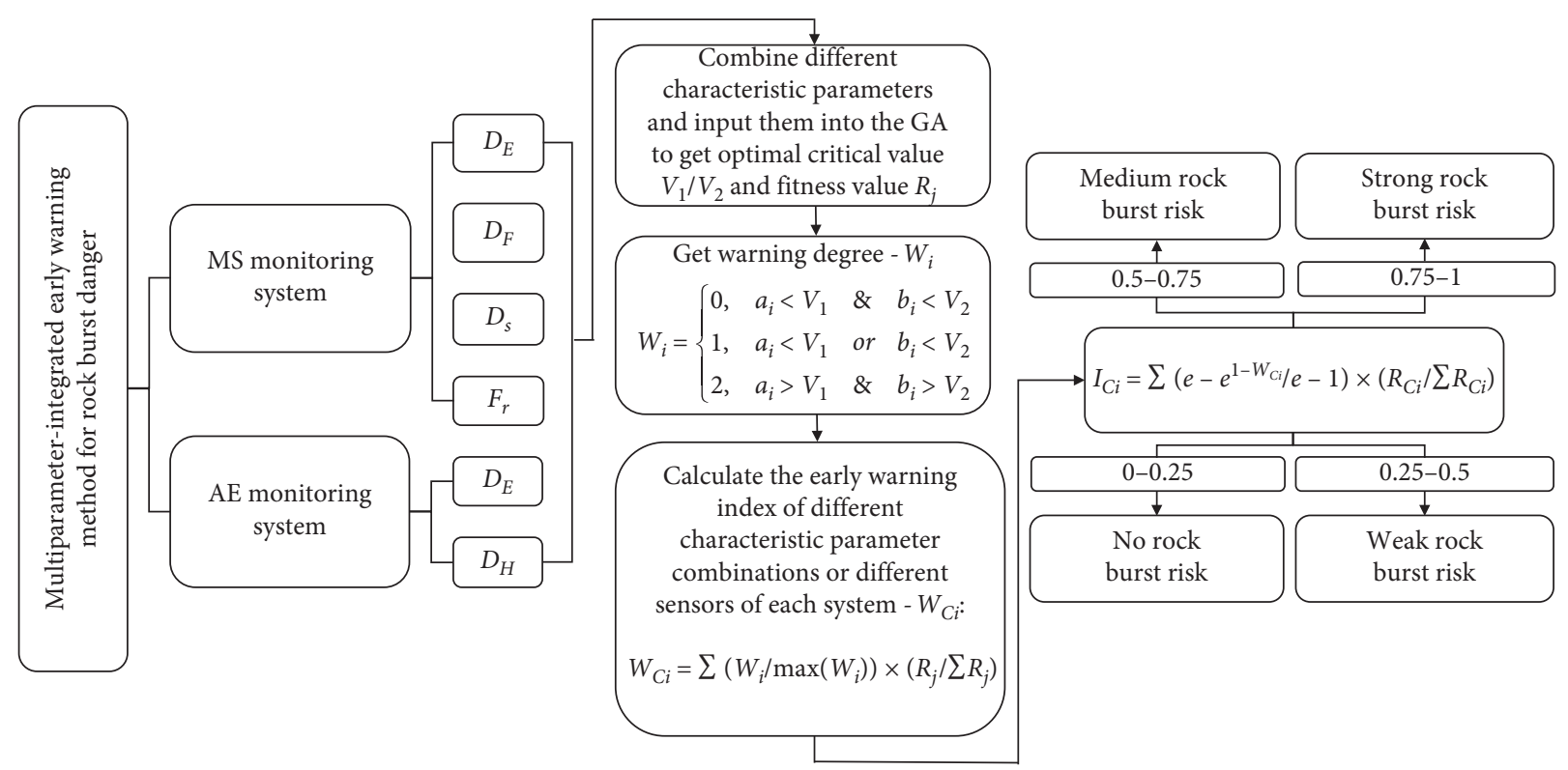

FIGURE 10: The flowchart of multisystem and multiparameter integrated early warning method of rock burst risk in WCM. 
TABLE 5: Early warning capability of different monitoring systems.

\begin{tabular}{llllllll}
\hline Name of the monitoring system & $n_{1}^{1}$ & $n_{0}^{1}$ & $N_{1}$ & $N_{0}$ & $a$ & $d$ \\
\hline ARAMIS M/E MS monitoring system & 6 & 6 & 1686 & 7119 & 1 & 0.237 \\
KJ623 AE monitoring system & 4 & 6 & 323 & 7119 & 0.667 & 0.045 & 0.621 \\
\hline
\end{tabular}

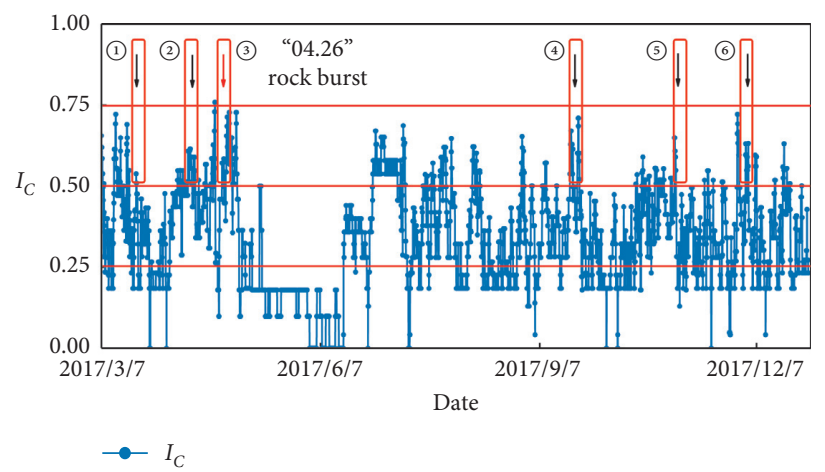

Figure 11: Multisystem and multiparameter integrated early warning index of rock burst risk.

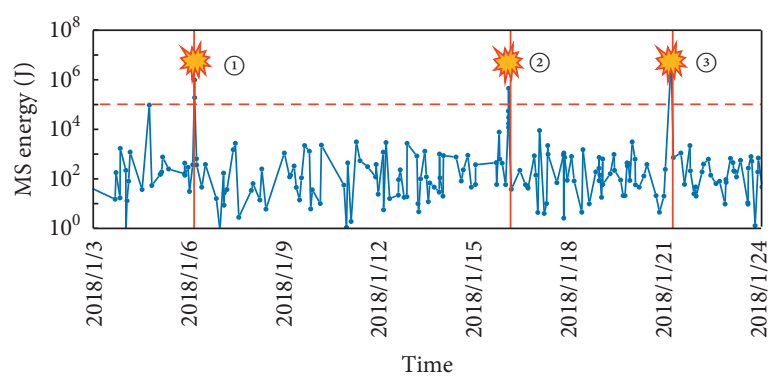

High energy tremor

Rock burst

-- Microseismic event boundary line $\left(>10^{5} \mathrm{~J}\right)$

(a)

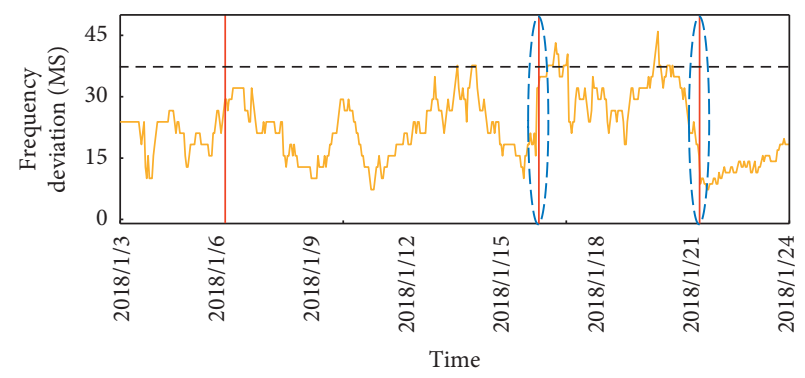

- - - Optimal threshold of characteristic parameters

... Correct warning

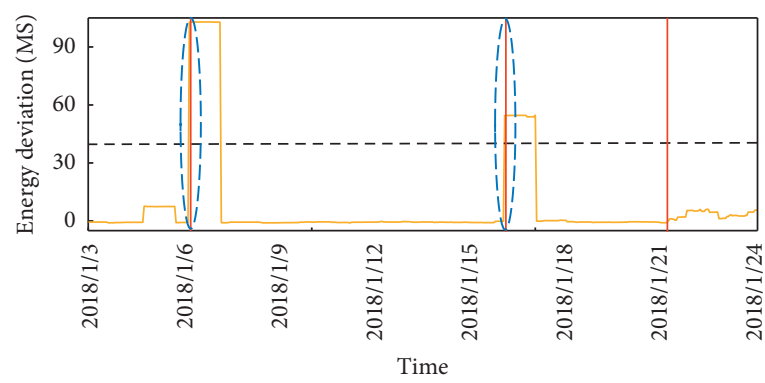

- - - Optimal threshold of characteristic parameters $\therefore$ Correct warning

(b)



- - Optimal threshold of characteristic parameters (-) Correct warning

(c)

(d)

Figure 12: Continued. 


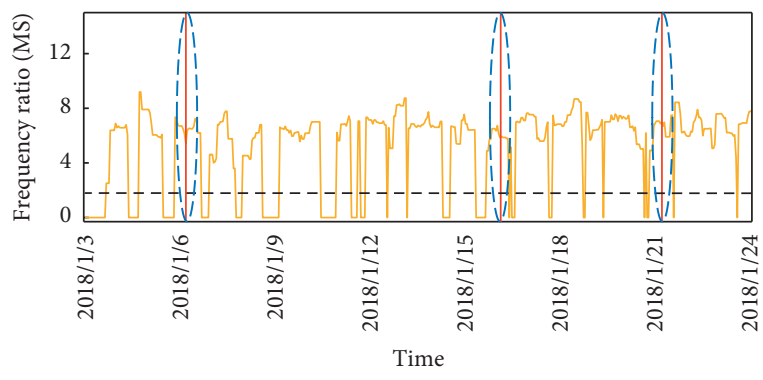

- - Optimal threshold of characteristic parameters -.) Correct warning

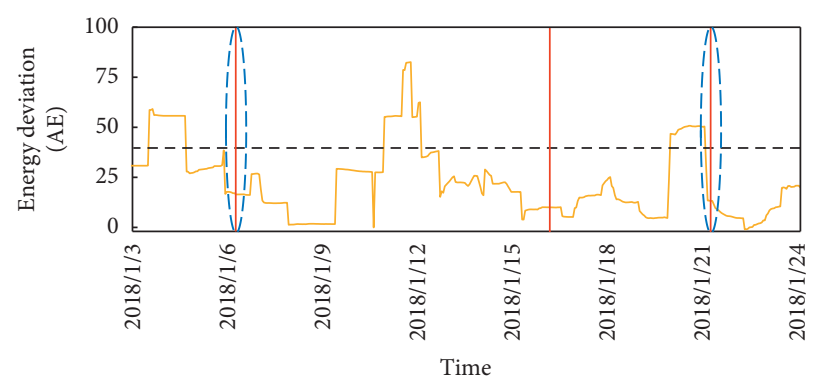

- - Optimal threshold of characteristic parameters - Correct warning

(e)

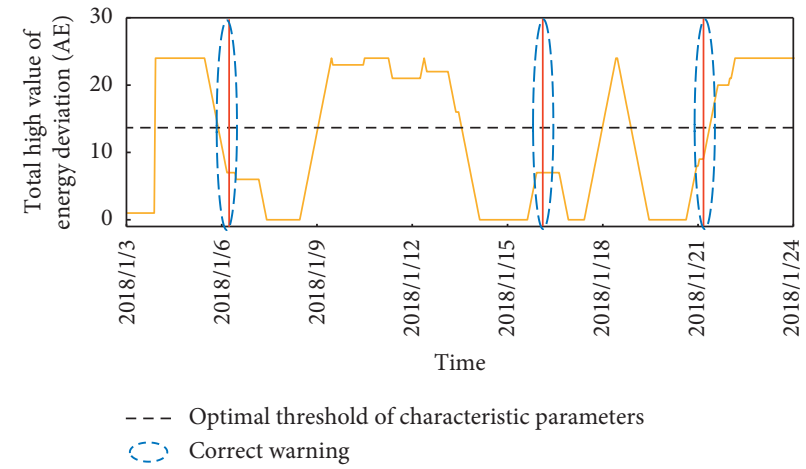

(g)

FIGURE 12: Time series curve of precursory characteristic parameters of each system in January 2018, (a) energy of MS event; (b) time series curve of $D_{E}$ of MS system; (c) time series curve of $D_{F}$ of MS system; (d) time series curve of $D_{S}$ of MS system; (e) time series curve of $F_{r}$ of MS system; (f) time series curve of $D_{E}$ of AE system; (g) time series curve of $D_{H}$ of AE system (1) 2018/1/6 04:30:48, 1.9 E+ 05 J; 2018/1/6 04: $30: 31,9.8 E+05$ J; (2) 2018/1/16 $01: 25: 45,4.50 E+05 \mathrm{~J}$; (3) $2018 / 1 / 2104: 07: 24,6.6 E+06 \mathrm{~J}$.

all events are numbered according to the sequence of (1)-(3). The time series curve of each precursor characteristic parameter for this time period is shown in Figure 12.

It can be seen from Figure 12 that the variation of each characteristic parameter has a significant correlation with the energy of MS tremor, which basically exceeds the optimal critical value for a period of time before the occurrence of the event and does not fluctuate much most of the time. Except that $D_{S}$ and $F_{r}$ are more sensitive than other parameters, it is low affected by noise and has high early warning capability.

Combined with the optimal critical value and fitness value of the same coal seam historical monitoring data, the real-time $I_{C}$ is calculated, and the calculation results are shown in Figure 13.

It can be seen from Figure 13 that the index in the red box has reached more than 0.5 within three days before the occurrence of the event, which is in the warning level of III or IV, and the number of false warnings is less, which greatly reduces the impact of early warning on normal production activities of the mine and achieves the balance between safe production and efficient production.

The verification results show that the method can reflect the rock burst risk status, specific risk areas, and levels of the current monitoring area in real time and quantitatively, eliminate the influence of subjective factors in the early warning process, and improve the accuracy of the early

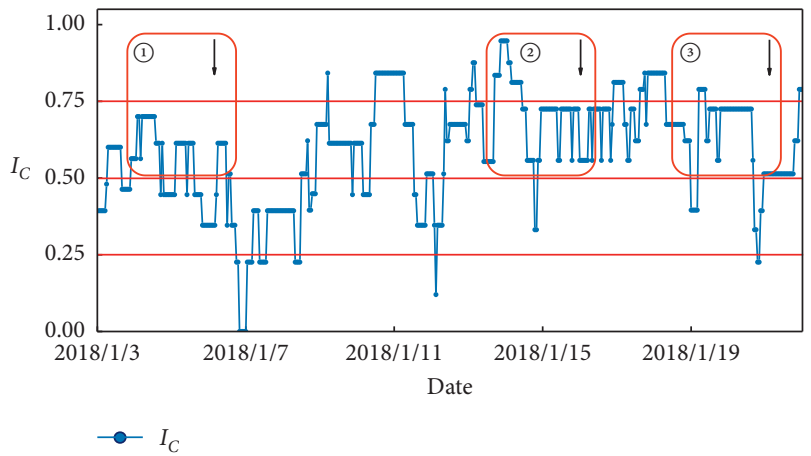

FIgURE 13: Integrated early warning index $I_{C}$ of rock burst risk in January 2018 (1) 2018/1/6 $04: 30: 48,1.9 E+05$ J; 2018/1/6 04:30: $31,9.8 E+05$ J; (2) $2018 / 1 / 1601: 25: 45,4.50 E+05$ J ; (3) $2018 / 1 / 21$ $04: 07: 24,6.6 E+06 \mathrm{~J}$.

warning of the rock burst risk. Combined with the different risk levels in Table 2, it can provide useful guidance for mining enterprises to prevent coal and rock dynamic disasters.

\section{Conclusion}

Rock burst often causes huge casualties and property losses, and accurate monitoring and early warning is the key to 
disaster prevention. Therefore, this paper constructs a multidimensional precursory characteristic parameter system, and proposes a multisystem and multiparameter integrated rock burst risk early warning method based on GA, which forms a highly reliable risk evaluation method with unified criterion, index, and critical value. The conclusions are as follows:

(1) Combining the GA with the $R$-value scoring method to optimize the critical value of the precursory characteristic parameters of each monitoring system, the optimal critical value and the corresponding early warning capability are obtained. The influence of missing or false warning is considered comprehensively, and the weight coefficients of each monitoring system can be adjusted according to the real-time calculation results. Under the long-term monitoring data, it still has high accuracy and can exclude the influence of subjective factors on the results in the early warning process.

(2) The multidimensional precursory characteristic parameter system of WCM is constructed, including energy deviation $\left(D_{E}\right)$, frequency ratio $\left(F_{r}\right)$, frequency deviation $\left(D_{F}\right)$, degree of dispersion $\left(D_{S}\right)$, and total high value of energy deviation $\left(D_{H}\right)$. The system combines the information of temporal-spatial-intensity rock burst incubation process with high accuracy and clear physical significance.

(3) The example shows that the proposed multisystem and multiparameter integrated rock burst risk early warning method has an early warning capability of 0.896, which is higher than 0.763 of the MS monitoring system and 0.621 of the $\mathrm{AE}$ monitoring system. It realizes the complementary advantages of multiple monitoring systems, improves the early warning accuracy, and further complements the early warning method of the underground dynamic disaster.

(4) The integrated early warning index $I_{C}$ of rock burst risk is proposed, which can reflect the change of rock burst risk in coal and rock in real time, and its quantification is divided into four levels. Combined with the specific measures corresponding to different risk levels, it can provide effective guidance for the disaster prevention work.

\section{Data Availability}

The .xlsx data used to support the findings of this study are included within the supplementary information file.

\section{Conflicts of Interest}

The authors confirm that there are no conflicts of interest associated with this publication.

\section{Acknowledgments}

The authors acknowledge Wudong coal mine for the provided raw data. This work was financially supported by the
National Natural Science Foundation of China (nos. 51634001 and 51774023), Beijing Nova Program (no. xx2018073), and the Fundamental Research Funds for the Central Universities (no. FRF-TP-19-024A2).

\section{Supplementary Materials}

The supplementary materials are the field monitoring data of Wudong coal mine, including the real-time data of MS and AE. (Supplementary Materials)

\section{References}

[1] Z. M. Xiao, J. Liu, S. T. Gu et al., "A control method of rock burst for dynamic roadway floor in deep mining mine," Shock and Vibration, vol. 2019, Article ID 7938491, 16 pages, 2019.

[2] P. Konicek and P. Waclawik, "Stress changes and seismicity monitoring of hard coal longwall mining in high rockburst risk areas," Tunnelling and Underground Space Technology, vol. 81, pp. 237-251, 2018.

[3] M. C. He, W. Nie, Z. Y. Zhao, and W. Guo, "Experimental investigation of bedding plane orientation on the rockburst behavior of sandstone," Rock Mechanics and Rock Engineering, vol. 45, no. 3, pp. 311-326, 2012.

[4] S. Akdag, M. Karakus, A. Taheri, G. Nguyen, and H. Manchao, "Effects of thermal damage on strain burst mechanism for brittle rocks under true-triaxial loading conditions," Rock Mechanics and Rock Engineering, vol. 51, no. 6, pp. 1657-1682, 2018.

[5] National Coal Mine Safety Administration 2019. http://www. chinacoal-safety.gov.cn/xw/mkaqjcxw/201907/t20190723_ 325304.shtml.

[6] W.-Y. Guo, T.-B. Zhao, Y.-L. Tan, F.-H. Yu, S.-C. Hu, and F.-Q. Yang, "Progressive mitigation method of rock bursts under complicated geological conditions," International Journal of Rock Mechanics and Mining Sciences, vol. 96, pp. 11-22, 2017.

[7] G. Liu, Z. Mu, and M. Karakus, "Coal burst induced by rock wedge parting slip: a case study in Zhaolou coal mine," International Journal of Mining, Reclamation and Environment, vol. 32, no. 5, pp. 297-311, 2018.

[8] G.-f. Wang, S.-y. Gong, Z.-1. Li, L.-m. Dou, W. Cai, and Y. Mao, "Evolution of stress concentration and energy release before rock bursts: two case studies from xingan coal mine, Hegang, China," Rock Mechanics and Rock Engineering, vol. 49, no. 8, pp. 3393-3401, 2016.

[9] T.-b. Zhao, W.-y. Guo, Y.-l. Tan, Y.-c. Yin, L.-s. Cai, and J.-f. Pan, "Case studies of rock bursts under complicated geological conditions during multi-seam mining at a depth of 800 m," Rock Mechanics and Rock Engineering, vol. 51, no. 5, pp. 1539-1564, 2018.

[10] D. Song, E. Wang, Z. Li, L. Qiu, and Z. Xu, "EMR: an effective method for monitoring and warning of rock burst hazard," Geomechanics and Engineering, vol. 12, no. 1, pp. 53-69, 2017.

[11] A. Hirata, Y. Kameoka, and T. Hirano, "Safety management based on detection of possible rock bursts by AE monitoring during tunnel excavation," Rock Mechanics and Rock Engineering, vol. 40, no. 6, pp. 563-576, 2007.

[12] J. He, L. Dou, S. Gong, J. Li, and Z. Ma, "Rock burst assessment and prediction by dynamic and static stress analysis based on micro-seismic monitoring," International Journal of Rock Mechanics and Mining Sciences, vol. 93, pp. 46-53, 2017. 
[13] P. Yan, Z. Zhao, W. Lu, Y. Fan, X. Chen, and Z. Shan, "Mitigation of rock burst events by blasting techniques during deep-tunnel excavation," Engineering Geology, vol. 188, pp. 126-136, 2015.

[14] J.-c. Wang, F.-x. Jiang, X.-j. Meng, X.-y. Wang, S.-t. Zhu, and Y. Feng, "Mechanism of rock burst occurrence in specially thick coal seam with rock parting," Rock Mechanics and Rock Engineering, vol. 49, no. 5, pp. 1953-1965, 2016.

[15] M. Cai, "Principles of rock support in burst-prone ground," Tunnelling and Underground Space Technology, vol. 36, pp. 46-56, 2013.

[16] M. I. Álvarez-Fernández, C. González-Nicieza, A. Argüelles, and A. E. Álvarez-Vigil, "Determination of the stress state in a rock mass subjected to excavation," Bulletin of Engineering Geology and the Environment, vol. 70, no. 2, pp. 243-253, 2011.

[17] G. Klee, A. Bunger, G. Meyer, F. Rummel, and B. Shen, "In situ stresses in borehole blanche-1/south Australia derived from breakouts, core discing and Hydraulic fracturing to $2 \mathrm{~km}$ depth," Rock Mechanics and Rock Engineering, vol. 44, no. 5, pp. 531-540, 2011.

[18] Z. H. Li, L. Y. Zhu, W. L. Yin, and Y. F. Song, "Study on monitoring rock burst through drill pipe torque," Shock and Vibration, vol. 2015, Article ID 371948, 8 pages, 2015.

[19] K. Matsuki, N. Kaga, T. Yokoyama, and N. Tsuda, "Determination of three dimensional in situ stress from core discing based on analysis of principal tensile stress," International Journal of Rock Mechanics and Mining Sciences, vol. 41, no. 7, pp. 1167-1190, 2004.

[20] C. Xu, Q. Fu, X. Cui, K. Wang, Y. Zhao, and Y. Cai, “Apparent-depth effects of the dynamic failure of thick hard rock strata on the underlying coal mass during underground mining," Rock Mechanics and Rock Engineering, vol. 52, no. 5, pp. 1565-1576, 2019.

[21] T. B. Zhao, W. Y. Guo, F. H. Yu, Y. L. Tan, B. Huang, and S. C. Hu, "Numerical investigation of influences of drilling arrangements on the mechanical behavior and energy evolution of coal models," Advances in Civil Engineering, vol. 2018, Article ID 3817397, 12 pages, 2018.

[22] L. Qiu, D. Song, Z. Li, B. Liu, and J. Liu, "Research on AE and EMR response law of the driving face passing through the fault," Safety Science, vol. 117, pp. 184-193, 2019.

[23] Z.-z. Zhang, F. Gao, and X.-j. Shang, "Rock burst proneness prediction by acoustic emission test during rock deformation," Journal of Central South University, vol. 21, no. 1, pp. 373-380, 2014.

[24] E. Wang, X. He, J. Wei, B. Nie, and D. Song, "Electromagnetic emission graded warning model and its applications against coal rock dynamic collapses," International Journal of Rock Mechanics and Mining Sciences, vol. 48, no. 4, pp. 556-564, 2011.

[25] X. He, W. Chen, B. Nie, and H. Mitri, "Electromagnetic emission theory and its application to dynamic phenomena in coal-rock," International Journal of Rock Mechanics and Mining Sciences, vol. 48, no. 8, pp. 1352-1358, 2011.

[26] M. C. He, J. L. Miao, and J. L. Feng, "Rock burst process of limestone and its acoustic emission characteristics under truetriaxial unloading conditions," International Journal of Rock Mechanics and Mining Sciences, vol. 47, no. 2, pp. 286-298, 2010.

[27] W. Cai, L. Dou, M. Zhang, W. Cao, J.-Q. Shi, and L. Feng, “A fuzzy comprehensive evaluation methodology for rock burst forecasting using microseismic monitoring," Tunnelling and Underground Space Technology, vol. 80, pp. 232-245, 2018.
[28] H. He, L. Dou, S. Gong, J. He, Y. Zheng, and X. Zhang, "Microseismic and electromagnetic coupling method for coal bump risk assessment based on dynamic static energy principles," Safety Science, vol. 114, pp. 30-39, 2019.

[29] X. Li, E. Wang, Z. Li, Z. Liu, D. Song, and L. Qiu, "Rock burst monitoring by integrated microseismic and electromagnetic radiation methods," Rock Mechanics and Rock Engineering, vol. 49, no. 11, pp. 4393-4406, 2016.

[30] S. He, D. Song, Z. Li et al., "Precursor of spatio-temporal evolution law of MS and AE activities for rock burst warning in steeply inclined and extremely thick coal seams under caving mining conditions," Rock Mechanics and Rock Engineering, vol. 52, no. 7, pp. 2415-2435, 2019.

[31] Z. C. Qin, T. Li, Q. H. Li, G. B. Chen, and B. Cao, "Combined early warning method for rock burst and its engineering application," Advances in Civil Engineering, vol. 2019, Article ID 1269537, 10 pages, 2019.

[32] Q. Lou, D. Song, X. He et al., "Correlations between acoustic and electromagnetic emissions and stress drop induced by burst-prone coal and rock fracture," Safety Science, vol. 115, pp. 310-319, 2019.

[33] Y. L. Tan, Y. C. Yin, S. T. Gu, and Z. W. Tian, "Multi-index monitoring and evaluation on rock burst in yangcheng mine," Shock and Vibration, vol. 2015, Article ID 624893, 5 pages, 2015.

[34] Y. X. Xia, H. Lan, and X. Z. Wei, "Study of comprehensive evaluation technology for rock burst hazard based on microseismic and underground sound monitoring," Journal of China Coal Society, vol. 36, no. S2, pp. 358-364, 2011, in Chinese.

[35] Y. M. Yin, F. X. Jiang, G. X. Xie et al., "Relation between coalrock failure and methane emission based on microseismic and dynamic stress monitoring," Journal of Mining and Safety Engineering, vol. 32, no. 2, pp. 325-330, 2015, in Chinese.

[36] J. G. Lv, Y. D. Jiang, Y. X. Zhao, J. Zhu, and F. Gao, "Hierarchical monitoring for coal bumps and its study and application of early warning methods," Journal of China Coal Society, vol. 38, no. 7, pp. 1161-1167, 2013, in Chinese.

[37] S. H. Liu, J. F. Pan, Y. X. Xia, Z. H. Qin, T. T. Du, and F. B. Chen, "Research on the risk hierarchical assessment of rock burst of heading face based on acoustic emission and electromagnetic wave CT system," Journal of China Coal Society, vol. 43, no. 8, pp. 2107-2116, 2018, in Chinese.

[38] J. H. Liu, M. H. Zhai, X. S. Guo, F. X. Jiang, G. J. Sun, and Z. W. Zhang, "Theory of coal burst monitoring using technology of vibration field combined with stress field and its application," Journal of China Coal Society, vol. 39, no. 2, pp. 353-363, 2014, in Chinese.

[39] R. S. Faradonbeh, S. S. Haghshenas, A. Taheri, and R. Mikaeil, "Application of self-organizing map and fuzzy c-mean techniques for rockburst clustering in deep underground projects," Neural Computing and Applications, vol. 32, pp. 8545-8559, 2020.

[40] Y. Xue, C. Bai, D. Qiu, F. Kong, and Z. Li, "Predicting rockburst with database using particle swarm optimization and extreme learning machine," Tunnelling and Underground Space Technology, vol. 98, pp. 1-12, 2020.

[41] S. C. Wu, Z. G. Wu, and C. X. Zhang, "Rock burst prediction probability model based on case analysis," Tunnelling and Underground Space Technology, vol. 93, p. 15, 2019.

[42] H. M. Li, Z. L. Li, R. J. He, and Y. B. Yan, "Rock burst risk evaluation based on particle swarm optimization and BP neural network," Journal of Mining and Safety Engineering, vol. 31, no. 2, pp. 203-207, 2014, in Chinese. 
[43] J. Zhou, X. Li, and X. Shi, "Long-term prediction model of rockburst in underground openings using heuristic algorithms and support vector machines," Safety Science, vol. 50, no. 4, pp. 629-644, 2012.

[44] A. C. Adoko, C. Gokceoglu, L. Wu, and Q. J. Zuo, "Knowledge-based and data-driven fuzzy modeling for rockburst prediction," International Journal of Rock Mechanics and Mining Sciences, vol. 61, pp. 86-95, 2013.

[45] Y. Lin, K. Zhou, and J. Li, "Application of cloud model in rock burst prediction and performance comparison with three machine learning algorithms," IEEE Access, vol. 6, pp. 30958-30968, 2018.

[46] K.-p. Zhou, Y. Lin, H.-w. Deng, J.-1. Li, and C.-j. Liu, "Prediction of rock burst classification using cloud model with entropy weight," Transactions of Nonferrous Metals Society of China, vol. 26, no. 7, pp. 1995-2002, 2016, in Chinese.

[47] J. Li, J. Yue, Y. Yang, X. Zhan, and L. Zhao, "Multi-resolution feature fusion model for coal rock burst hazard recognition based on acoustic emission data," Measurement, vol. 100, pp. 329-336, 2017.

[48] L. Wang, G. Xu, J. Wang, S. Yang, L. Guo, and W. Yan, "GASVM based feature selection and parameters optimization for BCI research," in Proceedings of the Seventh International Conference on Natural Computation, IEEE, Shanghai, China, July 2011.

[49] H. M. Pandey, A. Chaudhary, and D. Mehrotra, "A comparative review of approaches to prevent premature convergence in GA," Applied Soft Computing, vol. 24, pp. 1047-1077, 2014.

[50] H. Zhou, M. Song, and W. Pedrycz, "A comparative study of improved ga and pso in solving multiple traveling salesmen problem," Applied Soft Computing, vol. 64, pp. 564-580, 2017.

[51] K. Deb, "An efficient constraint handling method for genetic algorithms," Computer Methods in Applied Mechanics and Engineering, vol. 186, no. 2-4, pp. 311-338, 2000.

[52] K. Jong, "Learning with genetic algorithms: an overview," Machine Learning, vol. 3, no. 2-3, 1988.

[53] J. M. Fitzpatrick and J. J. Grefenstette, "Genetic algorithms in noisy environments," Machine Learning, vol. 3, no. 2-3, 1988.

[54] S. X. Xu, "Earthquake prediction method by seismicity," Acta Seismologica Sinica, vol. 15, no. 2, pp. 239-252, 1993, in Chinese.

[55] L. G. Luo, "Restudy on the method of scoring with $R$ value," North China Earthquake Sciences, vol. 22, no. 2, pp. 1-5, 2004, in Chinese.

[56] Z. L. Li, X. Q. He, L. M. Dou, D. Z. Song, G. F. Wang, and $\mathrm{X}$. L. Xu, "Investigating the mechanism and prevention of coal mine dynamic disasters by using dynamic cyclic loading tests," Safety Science, vol. 115, pp. 215-228, 2019.

[57] Y. X. Xia, L. J. Kang, Q. X. Qi et al., "Five indexes of microseismic and their application in rock burst forecastion," Journal of China Coal Society, vol. 35, no. 12, pp. 2011-2016, 2010, in Chinese.

[58] H. Q. Ma, C. H. Jin, W. X. Zhang, and W. J. Ma, "Further study and application of synthetical anomaly index," Earthquake, vol. 23, no. 4, pp. 27-31, 2003, in Chinese.

[59] H. T. Wang, Y. J. Qu, and R. He, "Study on comprehensive anomaly index based on various kinds of earthquake precursor anomalies," Inland Earthquake, vol. 16, no. 4, pp. 302-305, 2002, in Chinese. 